\title{
Assessment of Portal and Hepatic Hemodynamics after Side- to-Side Portacaval Shunt in Patients with Cirrhosis*
}

\author{
A. G. Redeker, $†$ C. T. Kunelis, $\$$ S. Yamamoto,$\S$ and T. B. Reynolds \\ (From the Department of Medicine, School of Medicine, University of Southern California, \\ and the Los Angeles County Hospital, Los Angeles, Calif.)
}

Interest in the side-to-side (SS) technique of portacaval shunting as opposed to the standard end-to-side (ES) technique was stimulated by the report of Longmire, Mulder, Mahoney, and Mellinkoff in 1958 of satisfactory results in 17 patients (1). They felt that preservation of the normal pathway of portal blood flow into the liver might be advantageous. Subsequent evidence indicated that after SS shunt there would be retrograde flow of hepatic arterial blood from the liver to the vena cava through the hepatic limb of the portal vein rather than forward flow of portal blood into the liver. Murray and Mulder $(2,3)$ and Long and Lombardo (4) found this to be the case in normal dogs following SS shunt. After SS shunt in cirrhotic patients, Longmire and his colleagues recovered radioiodinated serum albumin, after its injection into the hepatic artery (1), from the hepatic limb of the portal vein. At surgery, Warren and Muller found a rise in pressure in the portal vein near the liver when the portal vein was clamped on the hepatic side of an SS shunt (5). Contrast medium injected through a catheter placed in the portal vein near the liver has been noted to flow toward the vena cava $(1,5)$. SS and "doublebarrelled" portacaval shunts are thought to be more effective than ES shunts in relieving ascites, due to the greater lowering of presinusoidal pressure that occurs when some blood leaves the liver via the portal vein $(6,7)$. Our own studies in-

* Submitted for publication October 28, 1963 ; accepted March 9, 1964.

Supported by research grant HE 01718 from the National Institutes of Health, U. S. Public Health Service.

Presented in part to meetings of the American Association for the Study of Liver Diseases, Chicago, Ill., November 1, 1962.

$\dagger$ Recipient, Research Career Development Award, U. S. Public Health Service.

$¥$ University of Southern California research fellow. $\S$ China Medical Board research fellow. dicate that there is a greater fall in hepatic blood flow after SS shunt (8) than after ES shunt. The best explanation for this finding seems to be retrograde flow of hepatic arterial blood through the shunt. Although this type of circulatory effect from an SS shunt might at first be interpreted as a greater handicap to the liver than the complete diversion of portal blood provided by ES shunt, Farren and Muller (5) and Mulder and Murray (9) have suggested that retrograde portal flow actually may be helpful by increasing the total perfusion of the liver. For this to be true requires that hepatic arterial blood reach parenchymal cells before flowing backward in the portal venules. A limited amount of data obtained on patients does suggest a functional role for this blood. Warren and Muller found oxygen saturation levels of 70 to $86 \%$ in the hepatic limb of the portal vein after SS shunt in 6 patients. Mulder and Murray found greater extraction of both Bromsulphalein (BSP) and oxygen from retrograde flowing portal blood than from hepatic venous blood in 2 of 3 SS patients.

If, on the other hand, hepatic artery-portal vein connections exist at the presinusoidal levels, then the easier egress of blood from the liver afforded by SS shunt might impair functional hepatic blood flow. Murray and Mulder found that normal dogs did not do so well after SS shunt as after ES shunt and that the blood flowing retrograde in the portal vein invariably showed less clearance of oxygen and BSP than of hepatic venous blood (2). Studies at the time of portacaval shunt by our surgical colleagues, Mikkelsen, Turrill, and Pattison, also indicated less extraction of oxygen and BSP from backflowing portal blood than from hepatic venous blood (10). Our catheterization data suggest a greater decrease in hepatic oxygen uptake after SS shunt than after ES shunt (8). 
PORTAL AND HEPATIC HEMODYNAMICS AFTER SIDE-TO-SIDE PORTACAVAL SHUNT

TABLE I

Measurements at surgery in 18 patients undergoing portacaval shunt

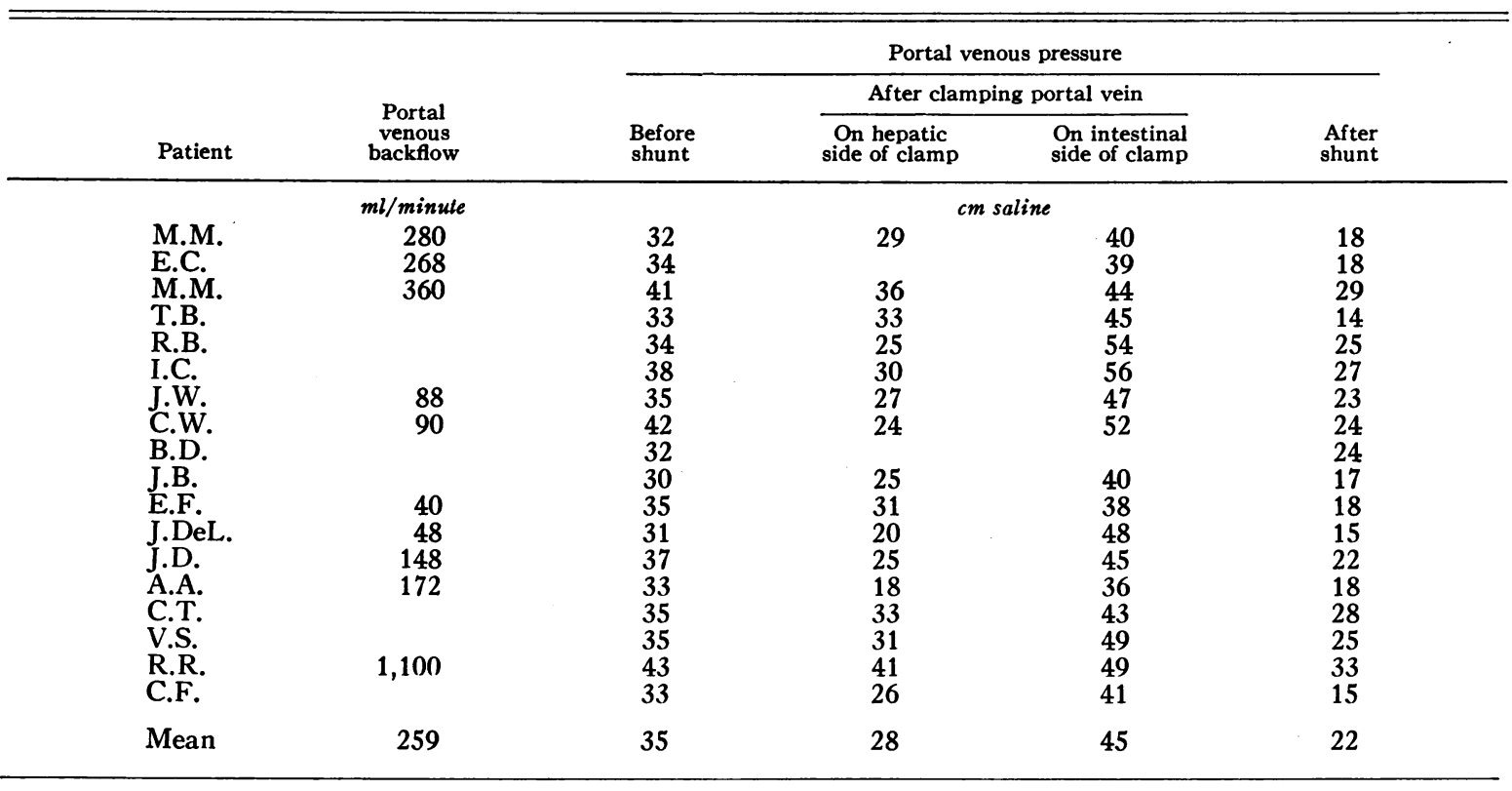

To study this problem further, we have made postoperative catheterization measurements in 18 patients with SS shunts. We have tried to determine the frequency of retrograde flow in the portal vein, the potential volume of this flow, and its functional contribution.

\section{Materials and Methods}

The patients were chronic alcoholics with esophageal varices and typical micronodular alcoholic cirrhosis confirmed by biopsy.

In all patients, at the time of surgery the pressure in the portal vein was determined with a saline manometer with its base at the level of the inferior vena cava (IVC), before and immediately after creation of an SS shunt. In 15 patients, the effect on portal venous pressure of cross-clamping the portal vein was measured. When the needle connected to the saline manometer was in place in the portal vein, the vein was alternately clamped on the intestinal and hepatic sides of the needle, and the change induced in the portal pressure was recorded. In 9 patients an effort was made to obtain an estimate of potential backflow of blood in the portal vein. When the vein was incised at surgery, a large, slightly tapered, polyethylene tube of approximately the same size as the portal vein was wedged in the vein in the direction of the liver. After allowing the flow to stabilize over a 10-second interval, the blood was allowed to flow freely from this tube, open to the air, into a collecting basin elevated $20 \mathrm{~cm}$ above the portal vein, for a 15- or 30-second period, and the volume of blood was measured in a graduated cylinder.

The catheterization studies were done from 19 days to 25 months postoperatively on fasting patients. A small incision was made to expose the saphenous vein just inferior to the junction with the femoral vein, and a no. 9 end-hole cardiac catheter was passed via the saphenous vein into the inferior vena cava. Vena caval pressure was measured, and the catheter was then passed through the SS portacaval anastomosis and directed toward the liver in the hepatic limb of the portal vein. The free and wedged portal venous pressures were recorded with a Statham electrical transducer positioned $5 \mathrm{~cm}$ posterior to the sternal angle of Lewis. The pressure levels reported in Table II are net pressures computed by subtracting the vena caval pressure from the measured portal venous pressure. The catheter tip was then positioned to lie free in the portal vein on the hepatic side of the portacaval shunt. A small amount of Bromsulphalein, from 100 to $150 \mathrm{mg}$, was injected into an arm vein, and approximately 10 and 15 minutes later, simultaneous blood samples were taken from the portal vein and the femoral artery. The concentration of BSP in the serum in each pair of samples was determined colorimetrically by the method of Gaebler (11). The percentage of oxygen saturation was also determined in each pair of samples with a Waters-Conley oximeter. The BSP and oxygen data recorded in Table II represent the average results of the two sampling periods. The percentage of BSP extraction by the liver from the portal vein blood was calculated by dividing the arterial-portal venous $\mathrm{BSP}$ difference by the arterial BSP concentration. 
TABLE II

Findings at postoperative catheterization of the portal vein through a side-to-side portacaval anastomosis in 18 patients*

\begin{tabular}{|c|c|c|c|c|c|c|c|c|c|c|}
\hline Patient & Age & Sex & $\begin{array}{l}\text { Direction of } \\
\text { blood flow } \\
\text { in portal } \\
\text { vein }\end{array}$ & $\begin{array}{l}\text { Free } \\
\text { PVP }\end{array}$ & $\begin{array}{l}\text { Wedged } \\
\text { PVP }\end{array}$ & $\begin{array}{c}\text { Arterial } \\
\text { BSP† }\end{array}$ & $\begin{array}{l}\text { Portal } \\
\text { BSP† }\end{array}$ & $\begin{array}{l}\text { BSP } \\
\text { extrac- } \\
\text { tion }\end{array}$ & $\begin{array}{c}\text { Arterial- } \\
\text { portal } \mathrm{O}_{2} \\
\text { differencet }\end{array}$ & $\begin{array}{l}\text { Hemo- } \\
\text { globin }\end{array}$ \\
\hline & & & & $m m ~ H g$ & $m m ~ H g$ & $\mathrm{mg} / 100 \mathrm{ml}$ & $\mathrm{mg} / 100 \mathrm{ml}$ & $\%$ & $\%$ & $\mathrm{~g} / 100 \mathrm{ml}$ \\
\hline M.M. & 47 & M & $\mathrm{R}$ & 5 & 17 & 2.08 & 1.82 & 13 & 21 & 12.4 \\
\hline E.C. & 55 & $\mathrm{~F}$ & $\mathrm{R}$ & 4 & 9 & 1.26 & 1.18 & 6 & 19 & 11.4 \\
\hline M.M. & 31 & $\mathrm{M}$ & $\mathrm{R}$ & 8 & 12 & 1.48 & 1.38 & $\begin{array}{c}7 \\
19+\end{array}$ & 13 & 10.8 \\
\hline T.B. & 29 & $\mathrm{~F}$ & $\mathrm{R}$ & & & 2.63 & $2.31^{+}$ & $12^{+}$ & $28^{+}$ & 10.0 \\
\hline R.B. & 62 & $\mathrm{M}$ & $\mathrm{R}$ & 7 & 4 & 2.15 & 2.17 & 0 & 0 & 12.2 \\
\hline I.C. & 26 & $\mathbf{M}$ & $\mathrm{R}$ & 2 & 3 & 1.42 & 1.23 & 13 & 23 & 9.4 \\
\hline J.W. & 45 & $\mathrm{~F}$ & $\mathrm{R}$ & 2 & 9 & 2.68 & 1.85 & 31 & 30 & 9.8 \\
\hline C.W. & 58 & $\mathrm{~F}$ & $\mathrm{R}$ & 3 & 0 & 4.10 & 3.88 & 5 & 16 & 11.8 \\
\hline B.D. & 56 & $\mathrm{~F}$ & $\mathrm{R}$ & 2 & 13 & 1.47 & 0.78 & 47 & 28 & 10.7 \\
\hline J.B. & 59 & M & $R$ and $F$ & & & 2.80 & 2.26 & 19 & 26 & 11.0 \\
\hline E.F. & 40 & $\mathbf{M}$ & $\mathrm{R}$ and $\mathrm{F}$ & 2 & 2 & 1.19 & 1.05 & 12 & 17 & 9.0 \\
\hline J.DeI. & 62 & M & $\mathrm{R}$ and $\mathrm{F}$ & 2 & 0 & 1.41 & 1.30 & 8 & 4 & 13.6 \\
\hline J.D. & 51 & $\mathbf{M}$ & $\mathrm{F}$ and $\mathrm{R}$ & 7 & 0 & 2.48 & 1.68 & 32 & 37 & 10.3 \\
\hline & & & Mean & 4.0 & 6.3 & & & 15.8 & 20.1 & \\
\hline A.A. & 48 & M & $\mathrm{F}$ & 8 & 0 & 2.24 & 2.24 & 0 & 11 & 10.8 \\
\hline C.T. & 37 & $\mathrm{M}$ & $\mathrm{F}$ & 17 & 0 & 3.67 & 3.72 & 0 & 16 & 12.0 \\
\hline V.S. & 48 & $\mathrm{~F}$ & $\mathrm{~F}$ & 12 & 3 & & & & 13 & 11.7 \\
\hline R.R. & 52 & $\mathrm{M}$ & $\mathrm{F}$ & & & & & & & 12.1 \\
\hline \multirow[t]{2}{*}{ C.F. } & $5 \overline{5}$ & $\mathbf{M}$ & $\mathrm{F}$ & 2 & 0 & & & & & 14.5 \\
\hline & & & Mean & 9.8 & 0.8 & & & 0 & 13.3 & \\
\hline
\end{tabular}

* $\mathrm{PVP}=$ portal venous pressure $; \mathrm{BSP}=\mathrm{Bromsulphalein} ; \mathrm{R}=$ retrograde $\mathrm{F}=$ forward.

$\dagger$ All values are the mean of 2 paired samples.

$\ddagger$ Simultaneous hepatic venous samples in patient M.M.

After the oxygen and BSP samples had been obtained, the catheter was again passed into the wedged portal position to repeat the measurement of wedged portal pressure and to confirm the wedged position by the injection through the catheter of 3 to $4 \mathrm{ml}$ of $50 \% \mathrm{Hy}-$

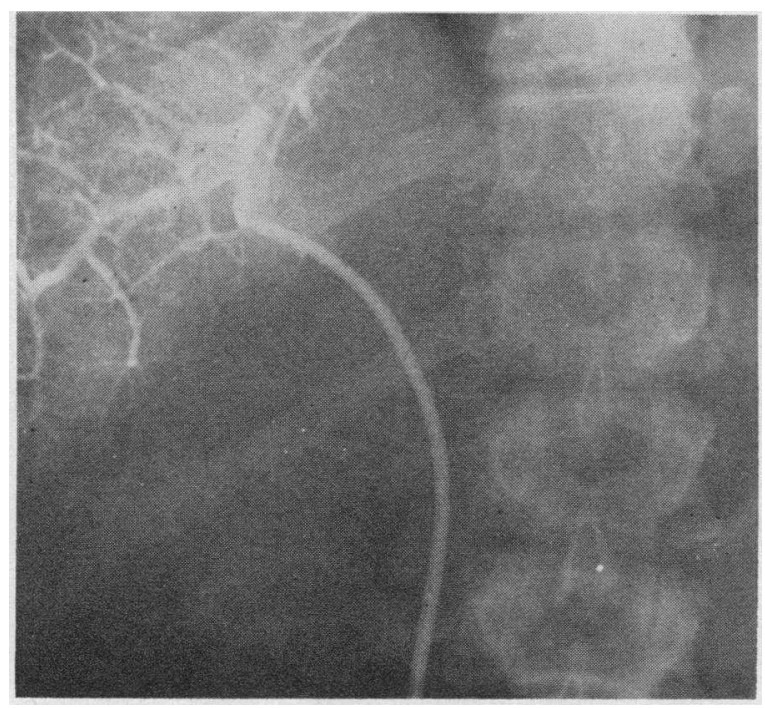

Fig. 1. Catheter in free portal vein (Patient C.T.). Contrast media has been injected, demonstrating forward flow of portal blood into the liver. paque 1 solution. Then, under continuous cinefluorography, the catheter was slowly withdrawn from the wedged position into the main portal vein and finally through the anastomosis into the IVC. While withdrawing the catheter, 10 to $15 \mathrm{ml}$ of a 50 or $75 \% \mathrm{Hy}-$ paque solution was continuously injected through the catheter with the least possible manual pressure, care being taken to avoid any bolus effect. The rate of injection was approximately 8 to $10 \mathrm{ml}$ per minute. In addition, in most patients, roentgenograms were taken at various locations in the portal vein after Hypaque injection and before the ciné recording. The direction of blood flow in the portal venous system was judged during the fluoroscopic observation and by inspection of the roentgenogram and the ciné records. In one patient (M.M.) hepatic vein catheterization was accomplished with a second catheter at the same time as the portal venous catheterization, and hepatic venous blood samples for oxygen and BSP content were obtained simultaneously with the portal venous and femoral arterial samples.

\section{Results}

Portal pressure measured at surgery, before the creation of the SS anastomosis, was elevated in all patients, averaging $35 \mathrm{~cm}$ saline (Table I).

\footnotetext{
1 Winthrop Laboratories, New York, N. Y.
} 


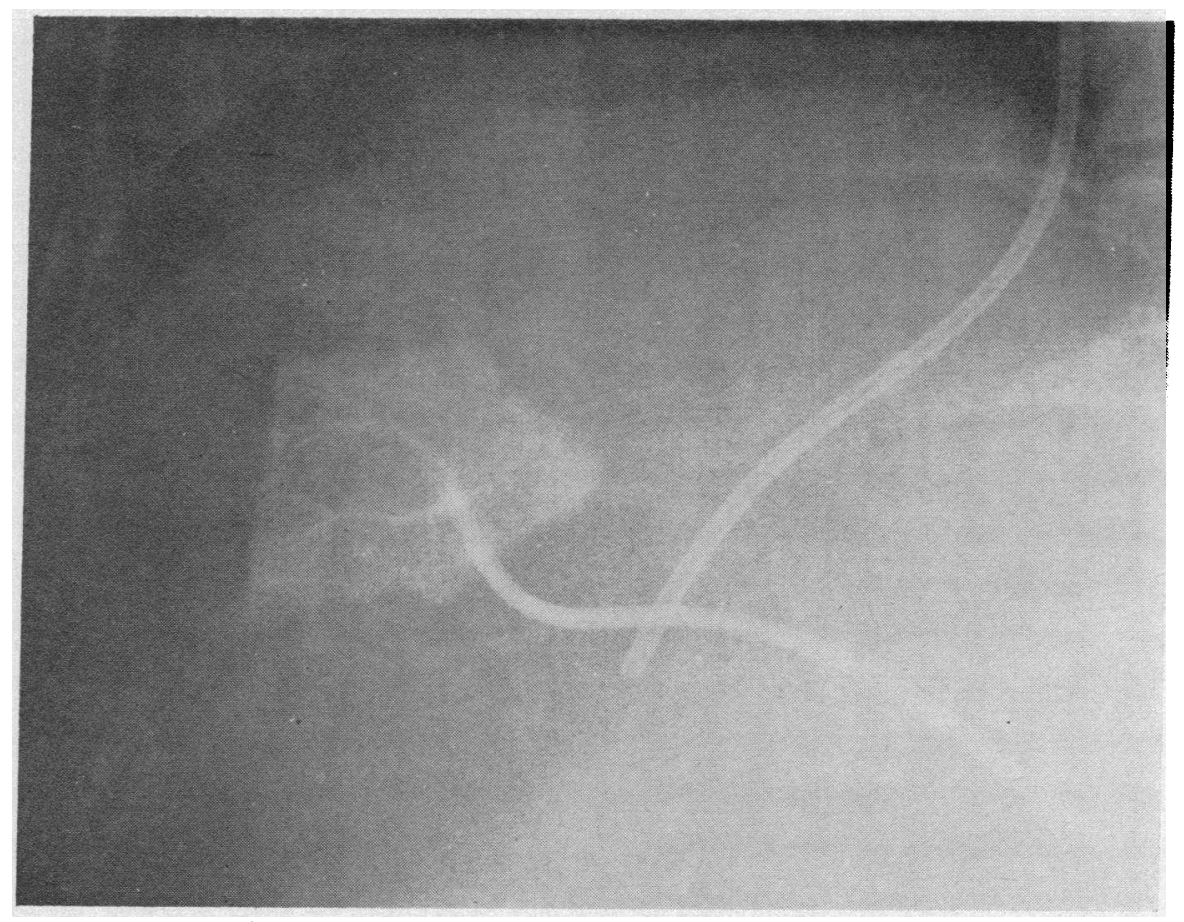

Fig. 2. LOWER CATHETER IS WEDGED IN THE PORTAL VEIN, AND CONTRAST MEDia has been injected, outlining the portal venous tRee (Patient M.M.). The upper catheter is in the hepatic vein.

It fell in all instances after opening the shunt, averaging then $22 \mathrm{~cm}$ saline. In 16 patients the pressure was determined on both the intestinal and hepatic sides of a clamp placed across the portal vein. Cross-clamping of the portal vein invariably caused a fall in pressure on the hepatic side of the clamp and a rise on the intestinal side. The average pressure change on the hepatic side was $-7 \mathrm{~cm}$ saline and, on the intestinal side, +10 $\mathrm{cm}$ saline.

In 10 patients, the rate of potential portal venous backflow through the large polyethylene tube ranged from 40 to $1,100 \mathrm{ml}$ per minute and averaged $259 \mathrm{ml}$ per minute (Table I).

The contrast medium injections demonstrated retrograde flow in the hepatic limb of the portal vein in 13 of the 18 patients (Table II). In 4 of these there was also some flow of contrast medium forward into the liver; it was difficult to decide the direction of predominant flow in 3 patients, whereas the flow was mostly forward in patient J.D. Changes in direction of flow with respiration were not obvious. In 5 patients all of the contrast medium flowed forward into the liver.
Figure 1 demonstrates forward flow in the free portal vein in patient C.T. Figure 2 shows a wedged portal contrast medium injection in patient M.M. with evidence of retrograde flow in withdrawal of the portal catheter (Figure 3).

In the 13 patients with retrograde portal blood flow, the arterial-portal venous oxygen difference ranged from 0 to $37 \%$ saturation and averaged $20.1 \%$ (Table II). BSP extraction from hepatic arterial blood ranged from 0 to $47 \%$, averaging $15.8 \%$ (Table II).

In 3 patients with forward flow of portal blood into the liver, there was an arterial-portal venous oxygen difference averaging $13.3 \%$ saturation, presumably due to splanchnic oxygen uptake. There was no arterial-portal venous BSP difference in the 2 patients in whom this was measured.

In those patients with retrograde flow, the portal venous wedged pressure exceeded the free portal venous pressure in 6 , was the same in 1 , and was less than the free portal venous pressure in 4 (Table II). The average portal wedged pressure in this group was $6.3 \mathrm{~mm} \mathrm{Hg}$, and the aver- 


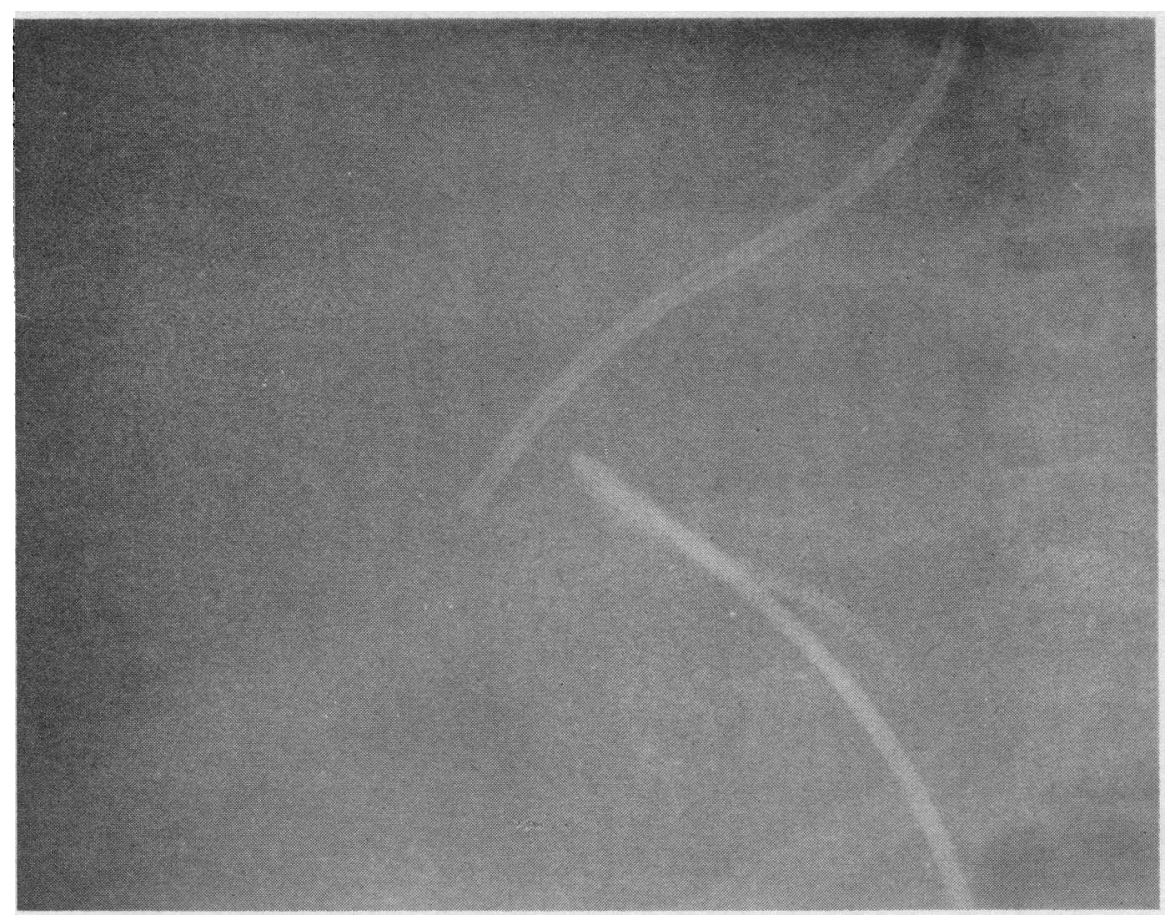

Fig. 3. The portal catheter has been withdrawn to lie free in the portal VEIN, AND CONTRAST MEDIA INJECTION SHOWS RETROGRADE FLOW TOWARD THE VENA CAVA (PATIENT M.M.). The upper catheter is in the hepatic vein.

age free portal venous pressure was $4.0 \mathrm{~mm} \mathrm{Hg}$ (Table II). In all the 5 patients with forward portal flow, the free portal venous pressure exceeded the wedged portal pressure. The average free portal pressure was $9.8 \mathrm{~mm} \mathrm{Hg}$, and the average wedged portal pressure was $0.8 \mathrm{~mm} \mathrm{Hg}$.

\section{Discussion}

The published data suggest that blood will always flow in a retrograde manner in the portal vein after SS shunt; however, in 5 of our 18 patients there was definite forward flow into the liver at the time of our catheterization study. Apparently, in some patients, hepatic arterial blood encounters less resistance in flowing through the hepatic veins than in traversing the portal venules and the shunt orifice. Persistence of forward flow was no doubt favored by an attempt by our surgical colleagues to keep the shunt orifice of moderate size (about $1.5 \mathrm{~cm}$ in diameter). Appreciable pressure gradients between portal vein and IVC ( 8 to $17 \mathrm{~mm} \mathrm{Hg}$ ) were still present at the time of the postoperative catheterization in
3 of our patients with forward flow. However, it is difficult to understand the definite forward flow in patient C.F. with portal venous pressure only $2 \mathrm{~mm} \mathrm{Hg}$ greater than IVC pressure. Also unclear is why free portal venous pressures were not lower than wedged portal venous pressures in 5 of our patients with definite retrograde flow. There may be unrecognized artifacts involved in recording wedged portal pressure; at any rate one clearly cannot make a valid decision regarding the direction of portal venous blood flow from these pressure measurements alone.

In 4 of our patients the flow of contrast medium away from the tip of the catheter in the portal vein was neither rapid nor decisively in one direction. Possibly there may be only a small flow of blood in the portal vein in some patients, and the direction of flow may vary from time to time depending on the circumstances.

Pressure measurements at surgery just before creation of the portacaval shunt did not provide evidence of preoperative retrograde portal venous flow in any of the patients in this report, whereas Warren and Muller found a sinusoidal 
pressure higher than the free portal pressure in 3 cases out of 7 , suggesting preoperative reversal of flow (5). Probably their patients were not a representative sample, since in preoperative pressure measurements by our surgical colleagues, evidence for reversed flow was found in only 7 of 61 patients (10). We have consistently (18 of 19 patients) found falls in hepatic blood flow after portacaval shunt, suggesting that portal blood does flow into the liver in most patients with cirrhosis $(8,12)$.

From our data the functional contribution of the blood leaving the liver in the portal vein appears quite variable. : In 3 patients (R.E., M.M., and C.W.) there was little or no extraction of either oxygen or BSP. On the other hand, in 3 patients (B.D., J.D., and J.W.) there was an appreciable fall in concentration of both substances from the arterial level. The average differences between arterial and portal venous levels of BSP and oxygen were $0.33 \mathrm{mg}$ per $100 \mathrm{ml}$ and $20.1 \%$ saturation, respectively. For comparison, the differences between arterial and hepatic venous levels of these same substances in a comparable series of SS shunt patients were $0.67 \mathrm{mg}$ per $100 \mathrm{ml}$ and $42 \%$ saturation (8). In the single direct comparison that we made (patient M.M.), hepatic venous $\mathrm{BSP}$ and $\mathrm{O}_{2}$ levels were $1.20 \mathrm{mg}$ per 100 $\mathrm{ml}$ and $64 \%$ saturation, and portal venous concentrations were 1.38 and $80 \%$ saturation. In only 1 of our patients (B.D.) was there anything approaching the remarkable $\mathrm{BSP}$ and $\mathrm{O}_{2}$ extractions from portal blood seen in a case studied by Mulder and Murray (9). Such examples must be exceptional as, probably, are cases like our R.B. with no extraction of either $\mathrm{O}_{2}$ or BSP.

Clearly the blood that flows from hepatic artery to portal vein after SS shunt has not, in most instances, traveled through functionless anastomoses. There has been exposure to hepatic cells, but either to a lesser degree than blood flowing in the normal manner to the hepatic vein, or the results of the exposure are less apparent because of a large volume of flow. Our assessment of portal venous backflow at surgery does not suggest the latter. The method used was admittedly crude but should provide a good estimate of the maximal possible backflow. Resistance in the large bore tube was low, and its diameter was about the same size as most of the shunt orifices.
There seemed to be no relation between the volume of potential backflow at surgery and the direction of flow postoperatively. The patient with the largest backflow measurement (R.R., 1,110 $\mathrm{ml}$ per minute) actually had definite forward flow at the time of the postoperative catheterization. It is interesting to compare the average value for potential backflow obtained in the patients in this study with the previously reported falls in hepatic blood flow (HBF) seen after ES and SS shunt $(8,12)$. Mean preoperative $\mathrm{HBF}$ in 19 patients undergoing portacaval shunt was $1,439 \mathrm{ml}$ per minute with no significant difference between the ES patients (1,493 $\mathrm{ml}$ per minute) and the SS patients $(1,380 \mathrm{ml}$ per minute). Postoperative HBF averaged $801 \mathrm{ml}$ per minute for the ES group and $497 \mathrm{ml}$ per minute for the SS group. The latter figure is clearly an overestimate of hepatic venous flow because of the removal of some BSP from the blood flowing out the portal vein. The increased HBF drop after SS shunt of somewhat more than $304 \mathrm{ml}$ per minute is of the same general order of magnitude as our estimate of portal venous backflow. This suggests that when retrograde portal flow does occur after SS shunt, it is at the expense of hepatic venous flow.

In hepatic venous catheterization studies before and after SS shunt, we found a fall in splanchnic oxygen consumption from a mean of $52 \mathrm{ml}$ per minute to a mean of $32 \mathrm{ml}$ per minute (8). Although the preoperative figure represents splanchnic oxygen consumption and the postoperative one only hepatic oxygen consumption, the difference seemed great enough to indicate a reduction in hepatic oxygen uptake. Comparable figures before and after ES shunt, for example, were 55.5 and $43.8 \mathrm{ml}$ per minute. The demonstration of appreciable oxygen extraction from retrograde flowing portal blood makes this apparent fall of hepatic oxygen consumption after SS shunt much less significant.

The clinical results of SS shunt in the patients in this report were satisfactory and, in general, comparable to the results of ES shunt. A detailed analysis of these results is under way in a much larger group of patients and therefore will not be attempted here. However, having noticed in an earlier survey (10) an apparent higher postoperative incidence of encephalopathy in SS shunt patients, we were interested in correlating the di- 
rection of blood flow in the portal vein with the presence of this complication. Two patients with recurring severe encephalopathy (R.B. and C.W., ages 62 and 58) had reversed flow; however, the patient with the most severe encephalopathy (C.F., age 55) had forward flow. Sixteen of the 18 patients are alive, an average of 24 months after the surgery. C.F. expired after the first stage of a colon exclusion operation for chronic encephalopathy (after 29 months of follow-up), and R.B. died with hepatic failure and chronic encephalopathy, after a hip fracture (26 months of follow-up). There have been no episodes of gastrointestinal bleeding since surgery in the 5 patients with forward flow, and esophageal varices decreased in size in C.F. and A.A. Postoperative esophagoscopy has not been performed in V.S., C.T., or R.R.

If our interpretation of our observations is correct, there should be little difference between the hemodynamic effects of SS and ES shunt in most patients. Both will cause a loss of portal venous inflow that will lead to a reduction in hepatic venous outflow. In addition, after SS shunt, there will likely be some backflow of hepatic arterial blood through the proximal portion of the portal vein into the vena cava. This will not be large in amount but will result in a further reduction in hepatic venous flow. The backflowing blood will contribute to liver function and nutrition, although usually to a lesser extent than an equivalent amount of blood flowing into the hepatic vein. This contribution will tend to minimize the difference in hemodynamic effect that would otherwise be evident between the two types of shunts.

In a few patients portal blood will continue to flow toward the liver after SS shunt. This should result in less physiologic disturbance from the operation, although if it is accomplished by reducing the size of the shunt orific too much, there may be residual portal hypertension and persistence of varices.

\section{Summary}

In 18 patients with cirrhosis, pressures were measured in the portal vein at the time of side-toside portacaval shunt, and the potential backflow of hepatic arterial blood through the portal vein was estimated by allowing blood to flow freely out of the proximal end of the portal vein into a container. Postoperatively the hepatic limb of the portal vein was catheterized through the side-toside shunt for determination of the direction of portal blood flow and the amount of BSP and oxygen extraction.

There was backflow of hepatic arterial blood into the portal vein postoperatively in 13 of the 18 patients. Where forward flow persisted postoperatively, it was usually associated with some degree of continued elevation of pressure in the portal vein. The maximal potential portal venous backflow estimated at surgery averaged $259 \mathrm{ml}$ per minute. At the time of catheterization, the backflowing venous blood contained 0 to $47 \%$ (mean, 15.8) less BSP and 0 to $37 \%$ (mean, 20.1) saturation less $\mathrm{O}_{2}$ than arterial blood, indicating variable contract of the backflowing blood with hepatic cells.

Retrograde flow of hepatic arterial blood into the portal vein after side-to-side portacaval shunt should result in a greater reduction in hepatic venous flow than after end-to-side shunt, as we have previously reported. However, the relatively small volume of this backflow and the fact that it contributes somewhat to liver function make the physiologic disturbance from side-to-side shunt little different from that following end-to-side shunt.

\section{References}

1. Longmire, W. P., Jr., D. G. Mulder, P. S. Mahoney, and S. W. Mellinkoff. Side-to-side portacaval anastomosis for portal hypertension. Ann. Surg. 1958, 147, 881.

2. Murray, J. F., and D. G. Mulder. The effects of retrograde portal venous flow following side-toside portacaval anastomosis: a comparison with end-to-side shunts. J. clin. Invest. 1961, 40, 1413.

3. Mulder, D. G. The role of surgery in the treatment of portal hypertension. Amer. J. Gastroent. 1960, 33, 305.

4. Long, R. T. L., and C. R. Lombardo. Hemodynamic observations on the hepatic circulation: modifications produced by portacaval shunting (abstract). J. clin. Invest. 1959, 38, 1021.

5. Warren, W. D., and W. H. Muller, Jr. A clarification of some hemodynamic changes in cirrhosis and their surgical significance. Ann. Surg. 1959, $150,413$.

6. McDermott, W. V., Jr. The treatment of cir- 
rhotic ascites by combined hepatic and portal decompression. New Engl. J. Med. 1958, 259, 897.

7. Welch, C. S., H. F. Welch, and J. H. Carter. The treatment of ascites by side to side portacaval shunt. Ann. Surg. 1959, 150, 428.

8. Reynolds, T. B., W. P. Mikkelsen, A. G. Redeker, and H. S. Yamahiro. The effect of a side-to-side portacaval shunt on hepatic hemodynamics in cirrhosis. J. clin. Invest. 1962, 41, 1242.

9. Mulder, D. G., and J. F. Murray. An evaluation of the side-to-side portacaval shunt. Surg. Forum 1960, 11, 278.
10. Mikkelsen, W. P., F. L. Turrill, and A. C. Pattison. Portacaval shunt in cirrhosis of the liver. Clinical and hemodynamic aspects. Amer. J. Surg. 1962, 104, 204.

11. Gaebler, O. H. Determination of bromsulphalein in normal, turbid, hemolyzed or icteric serums. Amer. J. clin. Path. 1945, 15, 452.

12. Redeker, A. G., H. M. Geller, and T. B. Reynolds. Hepatic wedge pressure, blood flow, vascular resistance and oxygen consumption in cirrhosis before and after end-to-side portacaval shunt. J. clin. Invest. 1958, 37, 606. 